\title{
Jazz Space: Stabbing [Building] In the Dark
}

\author{
NATHANIEL BELCHER \\ Ohio State University/Tulane University
}

USA

And although modern science and technology are the same whether in New York, Paris, London, Accra, Cairo, Berlin, Moscow, Tokyo, Peking or So Paulo, Jazz is the only true international medium of communication current in the world today, capable of speaking creatively, with equal intensity and relevance, to the people in all those places.

- Eldridge Cleaver, Soul on Ice

\section{THE HYBRID (A METAPHOR)}

The fascinating ability of culture to construct "newness" by intermixing known categories has become both more apparent and more prolific in the expanding possibilities of twentieth-century communication technology. We are witnessing the production of a staggering number of new forms, a period of vigorous cultural cross-fertilization on a scale previously unknown. In this context, the growth of new directions in architectural pedagogy can only be stimulated by a consideration of how the phenomenon of cross-constructing or hybridization might be expressed in architectural spaces.

In the Western Hemisphere the search for an architectural model of the hybrid might logically focus on Brazil, a region which offers the richest mixture of African, European, and indigenous cultural influences in the Americas. The hybridized conditions of Brazilian culture stem from the blending of both the Spanish and the Portuguese heritages with a strong surviving indigenous culture and the lively African population originally brought to that context as slaves. Additionally, the theoretical discourse about Brazilian identity historically insists on racial equality, and although barely evident in practical life, the ideal of racial equality does promote the hybrid or mulatto as the ideal of Brazilian beauty. In fact, the country as a whole could be said to identify with and idealize the hybrid figure.

Jazz music is also a hybrid form. It cannot be read as either a purely African or a purely European product but can be most fully understood only by considering how both African and European influences contributed to its development. Clearly emanating from the African sensibilities but played

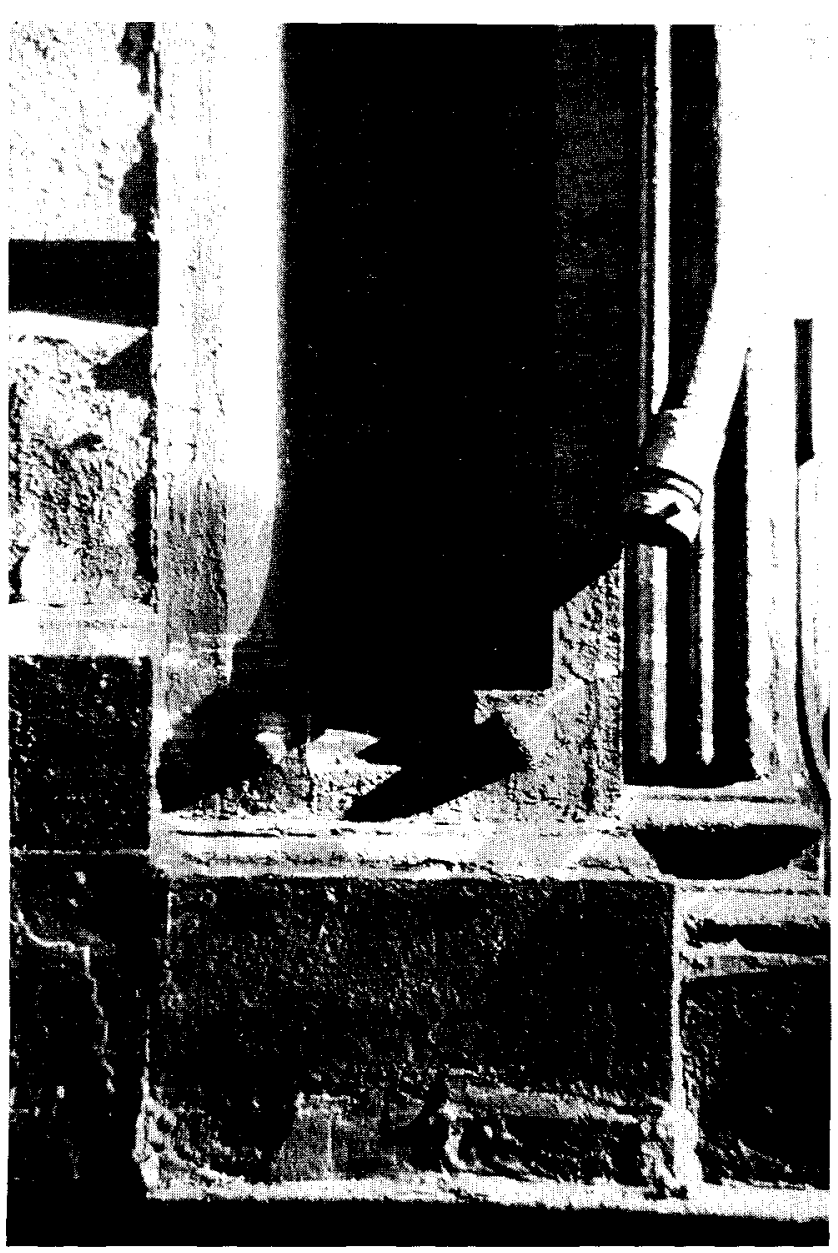

on predominantly European instruments, jazz is obviously an example of a cross-cultural genre, but it is also, less obviously, the product of the dynamic interaction between a dominant culture and a dominated subculture. Jazz took shape in relative obscurity and failed to attract significant attention from music theorists until late in its development. It therefore provides a useful example of a modern hybrid form developed both within a dominant cultural context and in isolation from it. As an instance of the hybrid in music, 
jazz is a stimulating model for considering instances of the hybrid in architecture.

The diversity of cultures typically celebrated in current architectural theory can be seen in actual building projects which contain complex cultural meanings, broadly recognizing peripheral, individualized experience while still reflecting the realities of our modern age. Such projects appear both in the center and in the periphery of the culture. In the center, they are often almost clinically controlled by theoryoriented architects and high-tech engineers, much as experimental hybrids are controlled in the life sciences. When peripheral to a recognized center, however, these hybrid products tend to be spontaneous, empirical and phenomenal. But the special advantage of architectural hybrids in the periphery is that they may advance to a significant level of development without being observed or interrupted by orthodox theoretical study. In this respect they are closely analogous to jazz: they are "jazz space."

Modernism in Brazil has emerged from a unique combination of factors: the simultaneous isolation from and exposure to other cultures together with a strong impulse to selfdefinition have produced a complex crisis of identity and, as an expression of that crisis, unique architectural forms. Most representative of these forms are the Brazilian favelas, the squatter communities on the outskirts of urban centers. Ultimately, the experience of traveling through a favela and that of listening to a piece of jazz music can both evoke rich critical and emotive insights useful to both disciplines.

\section{MODERNISM IN BRAZIL: A CARTESIAN JUNGLE}

Modernism in Latin America has always given a significant role to cultural expression, and the strongest and most lasting example of this tradition occurs in Brazil. Brazil has a curious relationship to modernity. In fact, the founding of the Brazilian Republic (1888) coincided with the onset of the Modern movement, and an enthusiastic Cartesian positivism is fundamental to Brazilian philosophy. But behind, within,

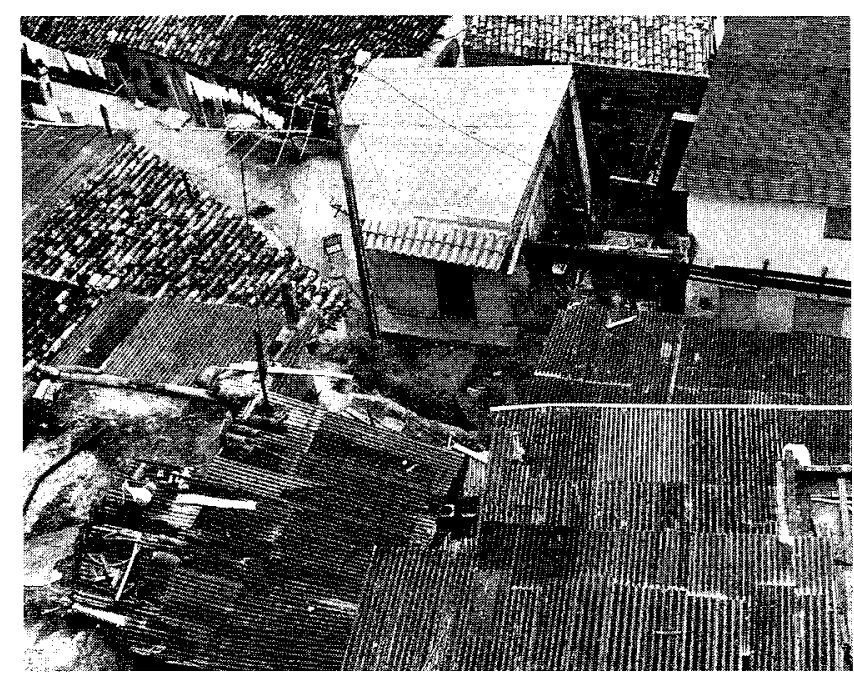

and supporting the Modernist insistence on order and fascination with scientific fact, there is a vibrant culture of people largely unconcerned with ideology as such yet driven toward positivistic images of progress and the future: to this day the words "Ordem e Progresso" ("Order and Progress") are on the flag. The Modernist movement has had such a fundamental influence on Brazilian culture that it may seem indigenous to it.

From its beginnings, Modernism subscribed to new ways of seeing as well as of expression, but it was often unfortunately preoccupied with reductive questions about universal instrumentality and scientism, overly concerned with the abstract, and oblivious of phenomenal realities. In reaction to these tendencies, Brazilian intellectuals proclaimed an alternative movement during the Modern Art Week of 1922 in So Paulo, a watershed event in the evolution of the Brazilian aesthetic. The new movement, while still intensely committed to the tenets of Modernism, asserted the validity of the indigenous cultural context and advocated supplementing the epistemic abstract with the mythical, ethnic, spiritual, and phenomenal elements of the native culture.

These claims shook the very basis of Brazilian theoretical pedagogy and led in subsequent years to a series of manifestos from the various arts. Among these was the Manifesto Antropofago ("cannibalist manifest") from the poet Oswaldo de Andrade, in which he satirically attacked traditional EuroBrazilian society with its simplistic colonial ideology in favor of a spirited modern recognition of the internal foundations of the Brazilian culture. This manifesto and others like it promoted a type of Modernism that savagely appropriated the central tenets of Modernism and reconstructed them for the context of the urban peripheries, the boundary zones between conventional Cartesian civilization and the surrounding jungle. This was a Modernism that could express the complex, indigenous, living identity of Brazil. Insistent on the immediacy of phenomenal experience and not constrained by rigid rationalism, this Modernism evokes an improvisational approach, one born out of the urgent--and often tragic--need for vernacular invention; it relies on the energy of spontaneity. No art form in North America more closely reflects this mixture of cultural forces than jazz, for jazz was produced from a similar kind of Modernism in its spontaneous counterconventional expression of lived experience. In jazz as in the outskirts of Brazilian cities, the empowering potential of an authentic, vital critique of Modernism is real and inescapable.

\section{MODERNISM | JAZZ : "IT DON'T MEAN A THING"}

Jazz is a solidly established, definable genre that originated in the marginal spaces of African-American culture, a fact that prompted Cornel West to call it the major art form created by Black Americans. It is also a uniquely American invention, integral and primal to the culture as a whole. As such, jazz has very successfully generated its own discourse, 
and it therefore can serve as a productive metaphor for hybrid space. It developed under distinct and novel conditions that inspired the splicing of rich African rhythms into the harmonics of European instruments. Emerging from the desire of marginalized people to celebrate their skills and their resourcefulness through musical expression, it was generated surreptitiously, in the margins, as a critique of the classical mode.

Luckily jazz was theorized only after it had developed an empirical, intuitive structure of sounds, processes and attitudes too securely established to be uprooted when early critics denied its significance. Although it uses tones and values which cannot be written in classical notation, there was no significant attempt to re-structure it for the sake of orthodox music theory; indeed music theory itself had to adapt to the existence of Jazz. By the time jazz attained intellectual legitimacy when music theorists documented and defined its essential characteristics, the fundamental properties of jazz had become well established in actual practice. The experience-based qualities that make Jazz an exceptional operation are primal to its very existence, for the two most prized properties of Jazz music remain improvisation and personalized production, and these qualities were able to emerge and mature as jazz incubated in the periphery. Jazz therefore owes much of its success as a musical form to the relative obscurity in which it developed, covertly, outside the range of educated critical ears, until it was "discovered."

Jazz is not about theoretical content: it is about responding to context on an immediate, visceral level. As the Duke Ellington lyric puts it, "It don't mean a thing if it ain't got that swing." That is why examining analogous impulses expressed in architectural space can deepen our understanding of how novel cultural conditions influence the production of responsive, living forms.

\section{BRAZILIAN ARCHITECTURE: ROMANTIC MODERNISM AND SHEER JOY}

The lively mixture of cultures that makes up Brazilian society has had a distinct effect on the architecture, producing innovative architectural forms as rich and diverse as the Brazilian culture. This hybrid context is perhaps best represented in Brasilia, the modern capitol, which reflects a conscious integration of the Brazilian spirit of culture with Modern forms largely influenced by Le Corbusier. Developed as a completely new city on a scale unmatched in any other contemporary context, Brasilia is the epitome of the hybrid Brazilian space.

Modern Brazilian architecture is often seen as flamboyant and excessive by outsiders, yet to many Brazilian architects its esoteric values are essential. The architecture of Lucio Costa, Oscar Niemeyer, Roberto Burle Marx and Lina Bo Bardi illustrates the effects of the Brazilian Modern architecture, which, even with its attempts to be modern, has always maintained a passionate interest in expressing Brazilian culture. In a recent monograph, Oscar Niemeyer and the Architecture of Brazil, David Underwood quotes Niemeyer as naming the Brazilian landscape, the samba, and the beauty of mulatto women among his significant poetic influences, influences he claims are essential to understanding the uniqueness of Modern architecture in Brazil.

The early collaborations of popular Brazilian architects with the French architect Le Corbusier in the 1930's, the 1946 Museum of Modern Art exhibition, "Brazil Builds," and several books published in the 1940's and 1950's all illustrate the effect of modern architecture on Brazil and indeed on all of Latin America. One book, Modern Architecture in Brazil by Henrique E. Mindlin, is particularly instructive about how the period was theorized and celebrated. This book presents an overview of Brazilian Modern architecture, edited to emphasize several of its primary interests and preoccupations. One was its fascination with the very existence of Modern architectural forms in what was considered a relatively primitive context. Another was its aspiration to integrate the iconography of the indigenous culture into the formal language of the architecture. But the most important characteristic of Brazilian Modern architecture was its obsession with the notion of progress. This architecture, it was thought, carried the capacity to propel the culture head-first into the "future"; in fact, the quintessentially Modern city of Brasilia stands as a marvelous example of this ambition expressed in architecture.

The assumption of the Brazilian architectural community of the 1950's was that this progressive drive would continue. However, for Brazil as for the rest of the world, the passage of time has changed many of the expectations of the 1950's. Economic cycles, political turmoil and material restrictions have contributed to this change, but so has the increasing visibility of indigenous and African-Brazilian cultural structures, creating a series of influences that have expanded the family of Modern architectural forms in Brazil.

Currently, Modern architecture in Brazil can be categorized into four general groups. The first of these types is the "High Modern" international style, architecture that reflects

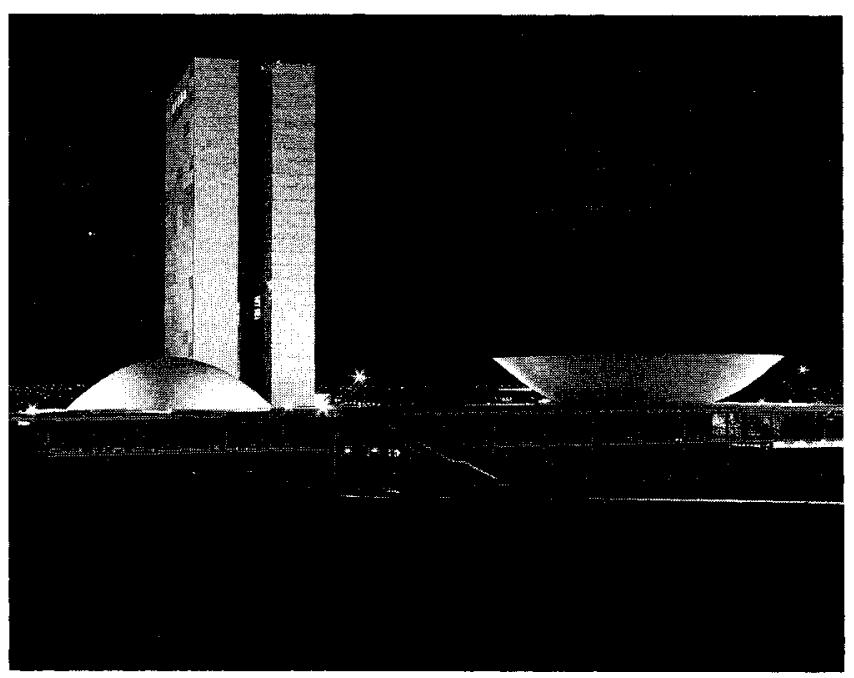


little regional or cultural influence. This class is comprised largely of the tourist architecture designed by foreign architects whose works make few apparent attempts to respond to the local culture, such as the 1950's proposal by Meis Van Der Roe for the American Embassy in Rio De Janeiro.

The second type is a form of Regional Modern architecture that is specifically adapted for construction in Brazil. This type includes the style of architecture called Brazilian Modernism, which incorporates processes and slight aesthetic inflections typical of the country. The architects of this group understand the principles of Modernism, yet they strive to give their work a clear sense of the Brazilian spirit. An important example of this group, Brasilia was designed to be a thriving contemporary, cosmopolitan city; however, the architect and the planner never lost sight of the idea that it was first and foremost a Brazilian city.

The third type is another variation of Regional Modernism, one that uses unique, specifically Brazilian building types and programs while still fundamentally adhering to the technologies and forms of Modern Architecture. Examples include the structures built throughout Brazil for the carnival parades, such as Oscar Niemeyer's Sambodromo, a massive concrete structure built for reviewing samba dancing. Another group of examples involves the Tropical Modern style, based on modern variations of the kinds of architectural conditions of enclosure that are only possible in tropical climates. In this group the mating of mild weather and modern form generates a seamless composition of interior and exterior spaces.

The fourth type of Brazilian Modern architecture involves novel forms of architecture spawned almost entirely from within the current culture, forms that are both Modern and truly indigenous to the country. These forms of architecture developed outside the arena of formal architectural criticism and cannot be attributed to any particular architect. They can be noted in the pervasive auto-construction and small-town architecture of Brazil that has adopted Modern forms while creating its own content. It is best exemplified by the favelas, the shanty towns built in the periphery of the major cities.

All four of these groups are dynamic and evolving, and although this classification is useful only to a point, it can help us understand the range of architectural styles found in the Brazilian hybrid. The foregoing classifications also help to position the favelas within the context of Brazilian Modern spaces. Perhaps the least welcome in the range of Modern Brazilian architecture, the favelas nevertheless represent the contemporary production of space for and by a population which is peripheral yet intensely engaged in a Modern hybrid culture.

\section{THE SPACE | SPONTANEITY}

Although Modernism influences both grand and humble architectural projects, it is difficult to construct an argument which celebrates the favelas as part of a conscious moder-

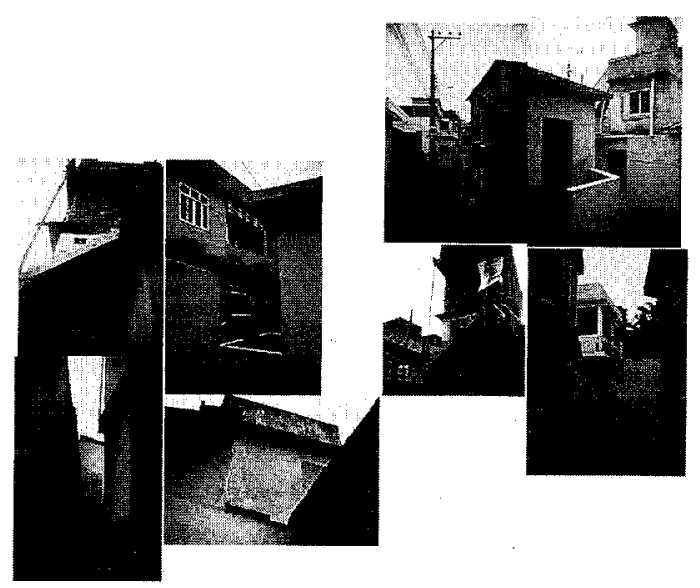

nity. After all, there is nothing new or romantically modern about poverty. The favelas have therefore been largely ignored in discussions of Modern architecture, most often excused as the unfortunate symptoms of economic crisis they are; however, they are also by-products of a vital populist power which has furtively created its own political, geographic, technical, economic, and aesthetic effects in the margins of the culture, and these effects in turn define a novel vision of Modernism.

These improvised cities are just as shocking, alluring, disturbing, engaging and modern as Brasilia: they simultaneously represent a modern crisis of place and an affirmative mode of self-preservation. It is therefore just as cynical and simplistic to discount the real influence of poverty on the favelas as it is to see Brasilia as a purely Eurocentric Modernist intervention; in both cases the lively cultural mix of Brazilian society has had a clear effect. Brazilian architecture, even with its attempts to be Modern, has always maintained a passion to be expressive of culture. But whereas Brasilia inspires awe with its visionary scale, the favelas reveal the inspiration of necessity and a tenacious optimism in the face of tragedy. In both cases the medium is space, and in both the space is energized by the blending of diverse cultural experiences and forms: they are both clear examples of the combination of collective and individual culture embodied in architecture.

Over the years, the favelas have evolved past their early image as the insubstantial sites of a flittering, ephemeral existence. They have emerged as cities in their own right, with political clout. No longer mere examples of the creative use of found materials, the favelas have mutated into permanent dwellings with community centers, school systems, and intricate infrastructures. Accepted as an established part of the urban context, the favelas have become an object of attention from the Brazilian government and private nonprofit agencies, which are attempting to work with and 
within the favelas and so to further legitimate their existence. As legitimate, definable places within the city, the favelas can be related to Modernism in several ways:

1. The favelas are Modern forms of architecture because they are created out of the real and inescapable conditions of the present era, the aesthetic, economic, political and social structures that define the culture of Brazil. One of the implicit features of Modernism is synchronicity, coherency or inherency, and the favelas are in many ways consistent with the conditions of contemporary Brazilian society.

2. The favelas reflect Modernism in that the techniques, forms, materials, and circumstances of their construction are fundamentally a part of modern conditions. Modern architecture amounts to far more than simple boxes; its materials and techniques are about necessity as well as availability. Furthermore, the same individuals that do much of the construction labor in more affluent parts of the cities also build in the favelas, bringing to the periphery an awareness of Modern forms and methods. Here one finds poured-in-place concrete, simple steel members, terra cotta blocks, and glass, together forming a palette of materials that work alongside mud-thatch, non-structural walls, hand-crafted wooden frames, tile mosaics, and traditional, natural pigments to produce structures that are strangely primitive as well as contemporary: the rudimentary materials and forms have been distilled to their bare essentials and mated with Modern sensibility to create intriguing, even tragically poignant forms of construction.

3. The favelas also relate to the Modern in the rituals of their construction, which are at once contemporary and traditional. For example, pouring a concrete pad is not a matter of merely ordering a truck but instead often involves an elaborate ritual of food, a community-wide project which can take days of laborious preparation culminating in a "fiesta" or party. Or take the case of the family tradition of building a room for every married daughter and her family: a small building must be structured to withstand the addition of several rooms one above another, resulting

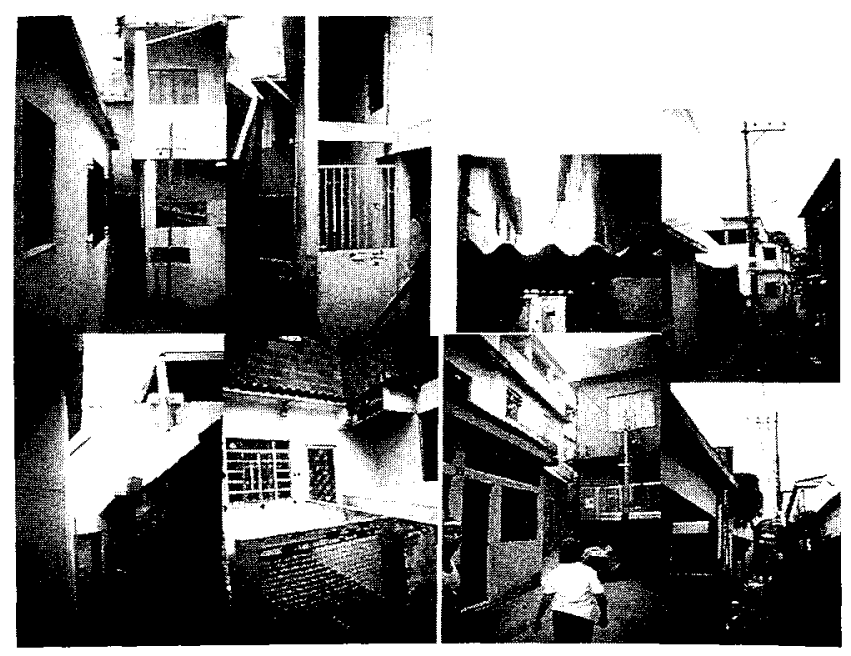

in simple vertical towers that embody the traditions of family structure in the crudest of Modern forms, the domino house. The social structure of the favela communities has prompted the adaptation of methods to improvise unique architectural structures, but the conditions that underlie these adaptations are essentially Modern.

4. Finally, the favelas reflect Modernism in the rituals of locating buildings. In contrast to the preplanned layout of many of our modern cities, the favelas developed much like an audience assembling in a park for a fireworks display: the spaces were claimed and squatted on haphazardly because they were available, undesirable or both. The result is a dynamic collection of interstitial spaces. Indeed the richest spaces exist between the simple structures, where buildings meet both gently and violently, creating intriguing and tragic spatial rhythms. These spaces are all the more challenged by their sites, for they are often located on swamps or hillsides, places that have forced builders to improvise site-specific forms and methods of construction. Some of these methods are beautifully inventive, others are excessive, and still others are tragically flawed; yet through empirical practice, workable systems are steadily developed to deal with the most diverse situations.

\section{JAZZ : A WARRANTED ANALOGY}

In another way...

What we have in both jazz music and the favelas is a disenfranchised population improvising novel forms using a fragmented array of available tools, techniques and materials, but these tools, techniques and materials are in no way the sole property of that population, nor is the modern dilemma of identity unique to Brazilians any more than it is to African Americans. This narrative, this myth, this story seeks to advance a larger agenda, one which acknowledges that the phenomena of architecture can gain inspiration from ritual, improvisation and immediacy. Jazz and the Brazilian favelas are both a posteriori products of Modernism; both are in every way dependent upon the mixture of traditional and modern influences, hybrids of colliding cultures and histories. They are each a product of modern culture re-formed in the hands of a diverse population, and each epitomizes the vigor of the empirical element in Modernism.

The best gift that jazz has given to music is the ability to criticize and redefine the form, content, and methodology of the more classical types of music. Just as that critical potential in jazz is fundamentally tied to the conditions our modern era, so Brazilian Modern architecture, especially that of the favelas, offers the possibility for a vital critique of architectural theory and practice. The people that live in these places are themselves involved in a way of redefining space, adapting it to express their needs and their dreams, just and as the original jazz musicians were involved in reshaping music. The favelas illustrate the lived experience of the Modern in the tradition of jazz music. It is because of all these similarities that I see in the Brazilian favelas what I call 


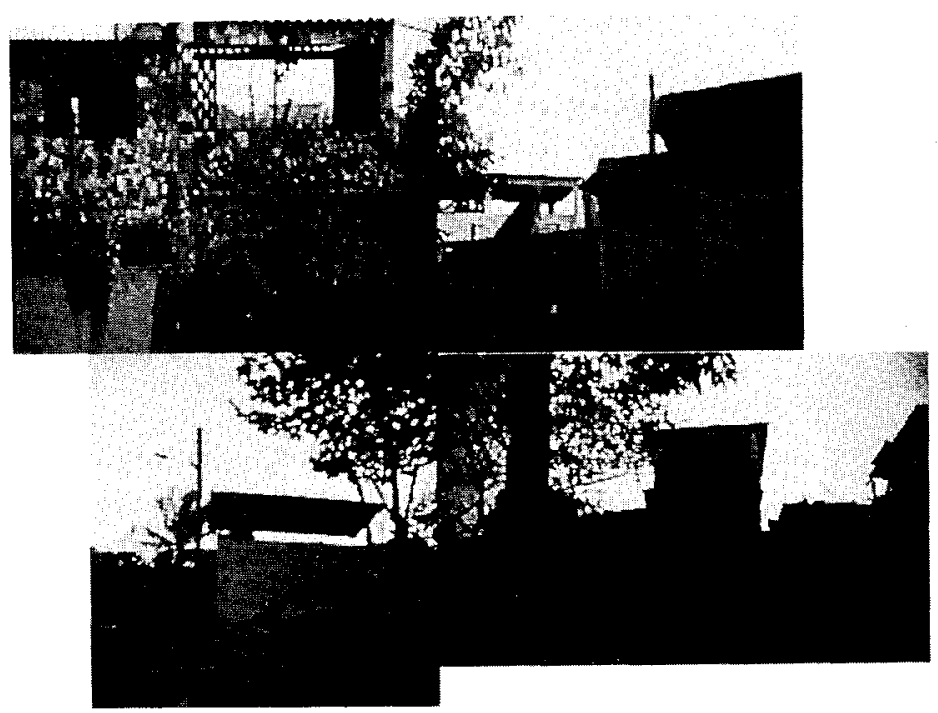

"jazz space," a type of space capable of challenging the canons of formal expression in architecture.

\section{AFTERWORD : AN ASIDE}

It is only through the discomfort of fragile connections we can discover new architecture. The reward of stabbing in the dark at ephemeral conceptions is the thrill of once again finding the body of our architecture. Subject and Soul. This is at once imagination and vision. The only danger is fetishization of phenomenon.

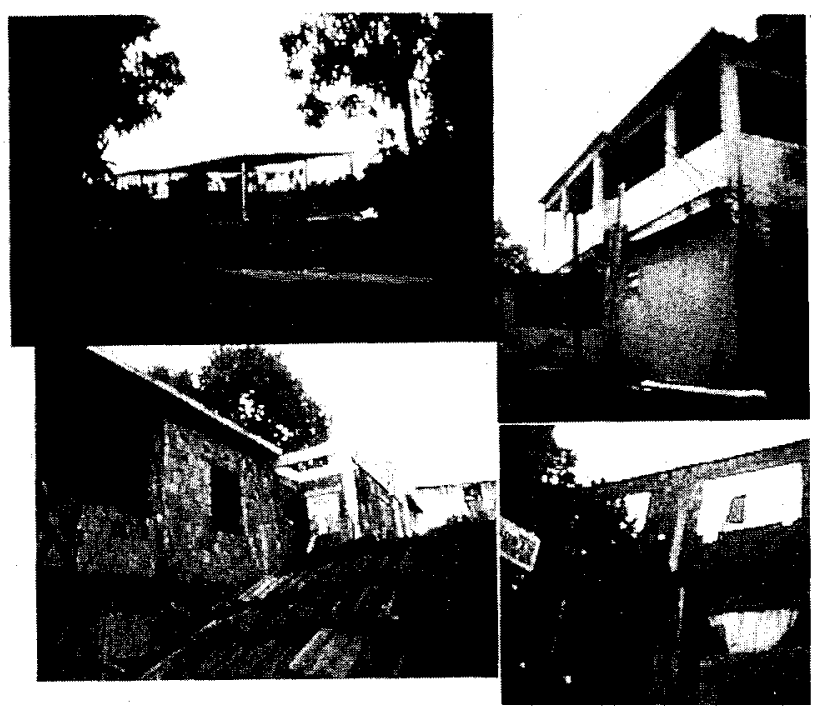

If you can imagine streams of passionate culture generating presence. . .

(The research for this paper involved a trip to Brazil which was funded by the Tinker Foundation and the Department of Architecture at Ohio State University. Addiitonal research support was provided by the National Endowment for the Arts, the School of Architecture of Tulane University, and the Jazz Architectural Workshop. This article was edited for publication by Linda E. Ford, English Department, Tulane University.) 